\section{Consideraciones sobre moda, estilo y tendencias}

Patricia Doria *

\begin{abstract}
Resumen: La Moda según Lipovetsky, se define como una búsqueda frenética de la novedad, y una forma de venerar el presente. Estos conceptos se encuentran relacionados entre sí y acordes a una sociedad abierta en una cultura en la cual los valores primordiales son el placer, la búsqueda permanente de pertenecer a un grupo y al mismo tiempo ser diferente, y único.

Esta exclusividad conlleva a tener o desarrollar un estilo específico. El estilo se define como un modo de expresión básico y distintivo, la relación del estilo con las modas, es del orden de lo general con lo particular. La moda en estos casos toma una posición de imperante y de regidora del mundo del buen gusto, pero aún así, hay pequeñas modas que se instauran dentro de otras esferas de no tanta envergadura y que son denominadas: estilos.
\end{abstract}

Palabras clave: arquetipo - estereotipos - estilo - macrotendencia - máscara - microtendencia - moda - tendencia.

[Resúmenes en inglés y portugués en las páginas 105-106]

(*) Master en Gestión de Diseño (en curso aprobación tesis, Universidad de Palermo). Diseñadora Indumentaria (Universidad de Buenos Aires). Docente Universitaria en la Universidad de Palermo y en la Universidad de Buenos Aires.

La moda es una forma especial de adornar y significar el cuerpo. Esta incide directamente en la identidad individual y colectiva. Se podría decir que es una manifestación de nuestro ser, identidad o estilo, influenciado por una tendencia actual en el mercado. Estas pautas de identidad están íntimamente asociadas a la vestimenta que decidimos llevar, según el contexto, la cultura, y la sociedad a la cual pertenecemos. Son transmisoras de información social y personal, por las cuales logramos hacer juicios de valor a través del vestuario que utilizan.

La Moda no es simplemente una manifestación de fatuidad sino que se convierte en un sistema permanente, como mencionamos anteriormente en una realidad social e histórica. Podemos definir a la Moda, como una búsqueda frenética de la novedad, y una forma de venerar el presente (Lipovetsky, 1990). Estos conceptos se encuentran relacionados entre sí y acordes a una sociedad abierta en una cultura en la cual los valores primordiales son el placer, la búsqueda permanente de pertenecer a un grupo y al mismo tiempo ser diferente, único, exclusivo.

Las tendencias por temporada primavera-verano, otoño-invierno han dado lugar a la superposición de estilos. El viejo y uniforme mecanismo de la Moda llamado por algunos autores cen- 
tenaria y por otros burguesa, en donde un diseñador marcaba pautas y tendencias, ha cedido el paso a una dialéctica de opciones y juegos donde se escoge no sólo entre diferentes modelos de indumentaria, sino entre los principios más antagónicos de la apariencia.

Lo primordial es el placer, la individualidad y la máscara, esa máscara que da imagen de equívoco y ambiguo, facilitando el traspaso de una manera de ser a otra muy distinta. Definiendo arquetipos y estereotipos a través, de un estilo.

En general se habla de estilo y en una forma muy indefinida, pero, ¿¿de qué se trata?:cómo el estilo se redefine y perdura a pesar de lo efímero y circunstancial de la moda? ¿cómo saber si las personas tienen o no estilo?, ¿cómo hacer para que perdure?, ¿ipor qué el estilo Jacky, Kelly, Haudrey? El estilo con el paso del tiempo se convierte en un ícono, ¿ícono de qué?.... y la respuesta es sencilla: ícono de estilo.

El estilo es un modo de expresión básico y distintivo, es el modo como están hechos los objetos a diferencia de cómo son los objetos en sí mismos, en líneas generales todos los estilos están integrados a la moda, es así, y si hablamos de moda hablamos de una representación de la tendencia, algo fugaz, efímero, y entonces, ¿cómo lograr que un estilo perdure y defina la imagen de un arquetipo a seguir?

La palabra estilo deviene del latín stilus (punzón) esta palabra designaba un instrumento puntiagudo que se utilizaba para la escritura, esta herramienta pasó a significar su forma peculiar de escribir, su "estilo" podía ser bueno o malo. También esta palabra se relaciona con un viejo verbo: stigo, stigare, stingere, y stimulare, con instigare. De estas palabras deriva estímulo, estimular e instigar. Pero siguiendo con la línea de análisis etimológico no se debe confundir el término latino stilus, con el griego, que significa "estar en pie", "columna" es decir la directriz que marca cual es el estilo a seguir. Esto es coincidente, si pensamos que el estilo, estimula, dirige, instiga, ordena, designa y deja una marca.

Este pasa a ser una forma de individualización; una forma de mostrarse distinto ante los demás y por ende, identificarse dentro de la masa como un ser único y especial. El estilo promete eternidad, y atemporalidad. Es considerado un recurso de autoconocimiento, una forma de identificación particular que genera en las personas una sensación de pertenecer a un mundo paralelo dentro del espectro de la moda, en donde ellos son los únicos protagonistas. De este modo, las personas se hacen portadoras de un estilo y esto marca la diferenciación.

Los estilos, no son formas paralelas de la moda sino que son integrantes de la misma; es muy común la confusión entre los términos moda y estilo, se habla de uno, cuando en realidad se quiere hablar de lo otro. La relación del estilo con las modas, es del orden de lo general con lo particular. La moda en estos casos toma una posición de imperante y de regidora del mundo del buen gusto, pero aún así, hay pequeñas modas que se instauran dentro de otras esferas de no tanta envergadura y que son denominadas: estilos.

Las tendencias como los estilos dan la impresión de ser algo místico, mágico y oculto (según los expertos), no sabemos de donde vienen, existen personas que los poseen y otras que no, da la impresión que ocurre sin más, que no se sustenta desde ningún concepto racional.

Las personas hacen diferentes inferencias a partir de datos iguales. ¿Por qué ocurre esto? Tiene que ver con la moda, en la cual las tendencias o desviaciones culturales modifican el pensamiento. La relación existente entre las variables moda y estilo, se dan como una relación unilateral, y no bilateral. La moda se basa en estilos. El estilo no se basa en una moda. Solamente cuando logra aceptación de gran cantidad de público, el estilo se convierte en moda. 
La cultura siempre distingue entre lo privado y lo público o entre lo nuevo y lo viejo o entre lo superior y lo inferior. Lo mismo hace la moda. Los objetos se utilizan del mismo modo para mostrar la distinción entre clases, las escalas de selección de productos, es decir, desde los más kitsch hasta lo más refinado y se va manteniendo en diferentes categorías y formas.

Las tendencias actuales en moda muchas veces están determinadas por una actitud de poder y de autoridad, (como mandatos subliminales) y esto va determinando el gusto estético estilístico. El cuerpo se estructura a través de un pensamiento de construcción, cuya representación es el vestido. Al parecer el cuerpo real cobra sentido a partir de la imaginación de un ideal. La moda tiene la capacidad de someter cualquier cuerpo (como una tabla rasa o una pared en blanco) al ideal imperante de la moda, es decir la capacidad de significarlo a través de una ilusión efímera, manejada por las tendencias y haciéndole creer al usuario que es libre y esa independencia lo autoriza a encontrar rápidamente un estilo propio.

En definitiva, cada estilo posee en sí mismo una cantidad de elementos enunciativos, con características especiales que hacen énfasis en distintos puntos corporales, como de reconocimiento, ocultamiento o manifestaciones de gustos y valores que están predeterminados por un período estipulado.

El estilo pasa a ser la forma de individualización dentro de la tiranía de la moda; es una forma de mostrarse distinto ante los demás y por lo tanto identificándose como un ser único y especial, este recurso puede ser utilizado para lograr una autoconocimiento, una forma de particularidad ante la generalidad, una sensación de pertenecer a un mundo paralelo en el cual esa diferencia los hace protagonistas con estilo.

La moda es impositiva, se elabora en una instancia social externa y las personas elaboran el origen de su decisión a partir de la mirada general, cada persona cree ser una pantalla en blanco de un sistema de moda que no lo consulta y lo convierte en su soporte, es decir, toma la decisión por ella.

Generalmente este carácter efímero, fugaz, imperativo y fragmentario que se le otorga a los estilos es erróneo desde el punto de vista que estas características son propias del fenómeno moda. La moda no sólo es fugaz; además disfruta de serlo, por características propias es efímera, por el contrario, el estilo propone eternidad, y se extiende en un tiempo que permite la insistencia de esas características en un modo de hacer y ver, configurándose en sí mismo por esa complejidad. El estilo tiene una extensión temporal y se basa en el aprendizaje social desde una multiplicidad de elementos comunicativos que son aceptados por una comunidad o conjunto social específico. Luego el paso del tiempo masifica esa exclusividad. El estilo deambula por diferentes propuestas no en una sola idea o un sólo soporte, ni en un sólo registro, como pueden hacerlo las modas o, también, los géneros de la comunicación. El estilo no se anuncia solamente en un objeto de diseño, y no se refiere únicamente a un problema de lenguaje, o en un lifestyle. Muchas veces un estilo se vuelve popular por diferentes circunstancias, y despierta el deseo de poseerlo. Ese fenómeno convierte un estilo en moda.

El estilo contiene en sí mismo elementos enunciativos que transitan significados, iconicidades, materiales, construcciones y lenguajes; es decir cada estilo incluye características especiales que determinan la fascinación o el rechazo de una época y el repudio o el alejamiento de los modos de percepción desde otras épocas. Por ende, los estilos en cada una de las épocas marcan sus estrategias diferenciales (ideal estético, pensamiento, sociedad, historia) construyendo una idea o significación vestimentaria que se incluiría finalmente dentro del llamado Sistema de la Moda. 
El estilo ya fue fundamentado por otro que no soy yo. Esto funda el imaginario de un personaje que nunca habla desde su yo real, los estilos en el vestir van adquiriendo una significación simbólica que facilitan el diálogo respecto a estilos de vida, clase económica, edad, formas, orientación sexual.

Como el estilo dispone, sí, de esos modos de hacer sentido, es en las estrategias de los estilos de época donde los actos de moda se emplazan como escudos, integrando un discurso de mayor complejidad. La inquietud que provoca el estilo prevaleciente en el arte y la moda de esta época debe seguramente parte de su intensidad al hecho de que aún ese emplazamiento y esa organización -de la moda en el estilo- se muestran ahora como provisorios y, aún, como conjeturales. Cada vez que se analiza el sistema de la moda, éste se entiende como un concepto global, donde las distintas áreas de la moda están condicionadas por cambios sociales y políticos los que determinan las macrotendencias, con su consecuente influencia en el arte, los negocios, la definición de arquetipos, y formación de microtendencias.

El sistema de la moda se entiende como un concepto global donde las distintas áreas de la moda están condicionadas por cambios sociales profundos, no sólo desde el diseño sino también desde la tendencia, la producción y la generación de nuevas oportunidades de negocio.

El término tendencia entraña todas las motivaciones compartidas colectivamente, que condicionan las elecciones del consumidor y dirigen su consumo. Podemos definir una tendencia como: propensión, inclinación o preferencia hacia lo que se tiende. La tendencias son premonitorias, porque primero se insinúan y luego cobran impulso. Las tendencias no son independientes, existe una fuerte interacción, incluso puede contradecirse, dado que reflejan los hábitos futuros del consumidor, y en general las personas se encuentran con muchas contradicciones. Las macrotendencias están afectadas por eventos sociales, políticos, culturales, hablan de las grandes preocupaciones de la humanidad, definidas en conceptos como, ecología, poder, tecnología. Las macrotendencias determinan una serie de patrones que modelan y dan carácter especial a la vida a nivel global, permitiendo ganar conocimiento sobre comportamientos futuros de aspectos claves que caracterizan a las sociedades, a las organizaciones y a los individuos y comprenden una previsión acerca de los aspectos fundamentales de diseño que se van a destacar en una determinada temporada.

Las macrotendencias se definen a través de las observaciones y análisis de distintas esferas de la realidad y permiten trazar las emergentes explorando relatos de futuro, estilos de consumo, traducibles a nuevos productos y servicios. Es imprescindible abarcar todo el abanico de realidades latentes en las sociedades. Analizadas desde un espectro político, económico, científico, ecológico, cultural y social, se proyectan en hábitos de consumo a largo plazo.

Las macrotendencias surgen y se desarrollan en un contexto social y espacio-temporal concreto, son tendencias sociales que trabajan en función de claves que suceden en la sociedad. Es un análisis de lo que está pasando en las principales ciudades del mundo. Es una introspectiva, y una proyección a tres años. Como la sociedad evoluciona, también lo hacen las claves y los conceptos que inspiran la creación de una colección.

Las microtendencias se entienden como la aplicación práctica en las cuales se analizan los desfiles, y los diseñadores más destacados de Nueva York, Londres, Milán y París, dando acceso a las microtendencias de temporadas de Moda específicas, nociones conceptuales en permanente evolución que se traducen a siluetas, colores, materiales, tipologías y detalles técnicos relacionados con nuevos usuarios. Se analizan todos los niveles del sistema de la moda como fashion 
shows, retails, streetwear, editoriales, publicidad, con proyecciones a corto plazo determinadas por las temporadas de moda.

Las tendencias perfilan a los consumidores que las empresas quieren atraer en los próximos años. Nos indican cómo se sentirán los consumidores, cuales serán las motivaciones de compra y qué estrategias productos y servicios aceptarán. Los datos psicológicos resultan más importantes que los datos demográficos. Los consumidores serán receptivos hacia aquellos productos que alivian la preocupación y reducen el estrés.

Las tendencias son premonitorias, porque primero se insinúan y luego toman impulso. Si las empresas pueden advertir la iniciación de la tendencia y el impacto que provocará sobre sus productos, pueden hacer los ajustes necesarios para aprovechar ese cambio. Las tendencias no son independientes, existe una fuerte interacción. Incluso pueden contradecirse, dado que reflejan los hábitos futuros del consumidor, y este es un personaje lleno de contradicciones.

Los diseñadores buscan ideas rupturistas e innovadoras que puedan aportar un toque distintivo a una colección, es decir, identificando los items o tips de temporada que se derivan de las microtendencias y los canalizan según su identidad y estilo personal. Luego esto impacta en sus colecciones de prendas en los distintos rubros que terminarán en las pasarelas de París, Milán, Londres, y Nueva York.

\section{Referencias Bibliográficas}

Barthes, R. (1967). Systeme de la mode. Trad. cast. Joan V. I. Sastre (1978). Sistema de la moda. Barcelona: Gustavo Gilli.

Lipovetsky, G. (1990). El imperio de lo efímero. La moda y su destino en las sociedades modernas. Barcelona: Anagrama.

Tungate, M. (2005). Marcas de Moda: Marcar estilo desde Armani a Zara. Barcelona: G. Gilli.

Summary: Fashion according to Lipovetsky, is defined as a frantic search for novelty, and a form of worship present. These concepts are interrelated and consistent with an open society in a culture where core values are pleasure, the constant search of belonging to a group and at the same time be different and unique.

This exclusivity implies to have or develop a specific style. The style is defined as a basic mode of expression and distinctive, the relationship with style and fashion goes from general to particular. The fashion in these cases takes a dominant position in the world of good taste, but still, there are small fads that establish themselves within other smaller areas and which are called styles.

Key words: archetype - fashion - macrotendency - mask - microtendency - stereotypes - style - trend.

Resumo: A moda, segundo Lipovetzky, se define como uma procura frenética da novedade, e uma maneira de venerar o presente. Estes conceitos se encontram relacionados entre eles e acordes a uma sociedade aberta numa cultura na cual os valores principáis são o prazer, a procura permanente de pertenecer a um grupo e ao mesmo tempo ser diferente e único. 
Esta exclusividade leva a desenvolver um estilo específico. O estilo se define como um modo de expressão básico e distintivo, a relação do estilo com as modas, é do ordem do geral com o particular. A moda nestes casos toma uma posição de imperante e de regidora do mundo do bom gosto, mais há pequenas modas que se instauram dentro de outras esferas de menor envergadura e que são denominadas estilos

Palavras chave: arquetipo - estereotipos - estilo - macrotendência - máscara - microtendência - moda - tendência. 